Public Health

Laboratory,

Gloucester Royal

Hospital,

Gloucester

GL1 3NN

K Cartwright

group director

Correspondence to:

Dr Goldblatt

d.goldblatt@

ich.ucl.ac.uk received a booster dose. H influenzae type b polysaccharide IgG responses are shown in the table. The proportions of children who had antibody titres below the minimum protective level of $0.15 \mu \mathrm{g} / \mathrm{ml}$ before receiving their booster dose at 1 year of age was higher than previously reported with the more extended primary immunisation schedule. ${ }^{5}$ The mean increase in antibody titre after administration of the booster dose was 803 -fold (95\% confidence interval 651 to 955 ).

\section{Comment}

This increase in antibody titres after booster immunisation is consistent with an immunological memory response, and shows that the children's immune systems were successfully primed by the three doses of conjugate vaccine they received during infancy. Immunological memory induced by vaccines administered

Geometric mean titre (95\% confidence interval) of Haemophilus influenzae type b polysaccharide $\operatorname{lgG}$, and the number (percentage) of infants with antibody titres below the minimum protective concentration $(0.15 \mu \mathrm{g} / \mathrm{ml})$ or above the long term protective concentration $(1.0 \mu \mathrm{g} / \mathrm{ml})$ after primary immunisation with three doses of conjugate vaccine, and immediately before and 1 month after a booster dose of the vaccine given at 1 year of age

\begin{tabular}{|c|c|c|c|c|}
\hline & \multirow[b]{2}{*}{ No } & \multirow[b]{2}{*}{ Geometric mean titre } & \multicolumn{2}{|c|}{ Antibody titre } \\
\hline & & & $<0.15 \mu \mathrm{g} / \mathrm{ml}$ & $>1.0 \mu \mathrm{g} / \mathrm{ml}$ \\
\hline After primary immunisation & 516 & 6.23 (5.53 to 7.01$)$ & $10(2)$ & $478(93)$ \\
\hline Immediately before booster dose & 401 & $0.41(0.35$ to 0.47$)$ & $153(38)$ & $126(31)$ \\
\hline 1 month after booster dose & 387 & 108.39 (91.62 to 128.23$)$ & $7(2)$ & $380(98)$ \\
\hline
\end{tabular}

according to the accelerated primary schedule may provide long term protection even when circulating antibody titres are low. Conjugate vaccines against $H$ influenzae type $\mathrm{b}$ could be introduced into the expanded immunisation programme of the WHO using a schedule of three doses in infancy and no booster dose. This should enhance deliverability and reduce costs.

Contributors: DG and EM designed the study. KC and EM coordinated the recruitment of patients and their follow up. DG and NM were responsible for developing the laboratory assay. The paper was written by all the authors. DG is guarantor for the study.

Funding: Medical Research Council. DG is a Welcome Trust Fellow.

Conflict of interest: None.

1 Mulholland K, Hilton S, Adegbola R, Usens S, Oparaugo A, Omosigho C, et al. Randomised trial of Haemophilus influenzae type-b tetanus protein conjugate for prevention of pneumonia and meningitis in Gambian infants. Lancet 1997:349:1191-7.

2 Steinhoff MC. Haemophilus influenzae type-b infections are preventable everywhere. Lancet 1997;349:1186-7.

3 Booy R, Heath PT, Slack MPE, Begg N, Moxon ER. Vaccine failures after primary immunisation with Haemophilus influenzae type-b conjugate vaccine without booster. Lancet 1997;349:1197-1202

4 Goldblatt D, Fairley CK, Cartwright K, Miller E. Interchangeability of conjugated Haemophilus influenzae type $\mathrm{b}$ vaccines during primary immunisation of infants. BMJ 1996;312:817-8.

5 Decker MD, Edwards KM, Bradley R, Palmer P. Responses of children to booster immunization with their primary conjugate Haemophilus influenzae type $\mathrm{B}$ vaccine or with polyribosylribitol phosphate conjugated with diphtheria toxoid. J Pediatr 1993;122:410-3

(Accepted 16 December 1997)
Public Health Directorate, Bro Taf Health Authority, Temple of Peace and Health, Cardiff CF1 3NW

Maria Z Morgan, research officer

Meirion R Evans, consultant in communicable disease control

Correspondence to: Dr Evans mre@abton4. demon.co.uk

BMJ 1998;316:1570-1

\title{
Initiatives to improve childhood immunisation uptake: a randomised controlled trial
}

\author{
Maria Z Morgan, Meirion R Evans
}

Levels of childhood immunisation are high in the United Kingdom but are proving difficult to maintain. Several initiatives to improve uptake have been described, including sending written information to parents, ${ }^{1}$ specialist immunisation clinics, ${ }^{2}$ and prompts to health visitors and general practitioners. ${ }^{3}$ However, none of these interventions has been the subject of a randomised controlled trial. We tested the effectiveness of two such interventions.

\section{Subjects, methods, and results}

The child health system, which maintains computerised data on immunisation status of all children, was used as the sampling frame. The study population comprised children resident in the former county of South Glamorgan who were (a) born between 1 April and 30 September 1995 and scheduled to complete the primary course of diphtheria, pertussis, tetanus, polio, and Haemophilus influenzae type b immunisation or $(b)$ born between 1 April and 30 September 1994 and scheduled to receive measles, mumps, and rubella immunisation. Children were included in the trial if they had not completed their primary course by
9 months of age or their measles, mumps, and rubella immunisation by 21 months of age.

Each week between 1 January and 30 June 1996 we received a computer generated list of children eligible for inclusion in the study and randomised each child using computer generated random numbers to one of two interventions or a control group. Intervention A comprised a non-directive telephone call to the child's health visitor to confirm the child's personal details and immunisation status. The health visitor was not informed of the trial and, although follow up of the child was anticipated, it was not specifically requested. Intervention B comprised a single mailed reminder to the child's parents together with a questionnaire about details of immunisation status and reasons for non-immunisation, and a reply paid envelope. Parents were not informed of the trial.

Study end points were completion of $(a)$ primary immunisation by the first birthday or $(b)$ measles, mumps, and rubella immunisation by the second birthday. We performed statistical analysis on an intention to treat basis, using the $\chi^{2}$ test with Yates's correction for baseline comparisons, and calculated 95\% confidence intervals for the difference in proportions. 
In total, 153 children (76 primary course and 77 measles, mumps, and rubella immunisation) were randomised to intervention A, 159 children (82 primary course and 77 measles, mumps, and rubella immunisation) to intervention $\mathrm{B}$, and 139 children (74 primary course and 65 measles, mumps, and rubella immunisation) to the control group. The study had a power of $80 \%$ to show a $15 \%$ difference between each intervention and the control group at 5\% two sided significance. Distribution of baseline characteristics in the three groups was similar. There was no significant difference between either intervention group and the control group in the proportion completing the primary course or measles, mumps, and rubella immunisation (see table). Nor was there a significant difference in study end point, when both interventions combined were compared with the control group. Subgroup analysis by maternal age and parity showed a substantial but non-significant effect of intervention in promoting completion of primary immunisation in firstborn children $(56 \%, 10 / 18)$ compared with firstborn controls $(25 \%, 3 / 12)$, and in children of young mothers aged $\leqslant 30$ years $(31 \%, 27 / 86)$ compared with controls $(13 \%, 5 / 38)$. There was no effect on uptake of measles, mumps, and rubella immunisation.

\section{Comment}

Randomised controlled trials provide the best evidence for effectiveness of interventions. However, we found only one other trial of an intervention to promote childhood immunisation. This was carried out in preschool children in the United States and found that a computer generated telephone reminder resulted in a significant but modest improvement of $12 \%$ in immunisation uptake in the intervention group, after excluding the $20 \%$ of households with no telephone. ${ }^{4}$

Neither intervention we studied improved immunisation uptake. The results suggest that district-wide initiatives directed at individual families are unlikely to be worth while, although there may be some benefit from targeting young or primiparous mothers. There is evidence that initiatives by primary healthcare teams such as opportunistic immunisation of children attending the surgery and domiciliary immunisation by nurses
Baseline characteristics and immunisation uptake in intervention and control groups. Values are numbers (percentages) of subjects unless stated otherwise

\begin{tabular}{lccc} 
& $\begin{array}{c}\text { Intervention A } \\
(\mathbf{n = 1 5 3 )}\end{array}$ & $\begin{array}{c}\text { Intervention B } \\
(\mathbf{n = 1 5 9 )}\end{array}$ & Control (n=139) \\
\hline Sex: & & & \\
\hline Male & $70(46)$ & $79(50)$ & $71(51)$ \\
\hline Female & $83(54)$ & $80(50)$ & $68(49)$ \\
\hline Ethnic group: & & \\
\hline White & $117(76)$ & $125(79)$ & $111(80)$ \\
\hline Other & $36(24)$ & $34(21)$ & $28(20)$ \\
\hline Mean (SD) maternal age (years) & $28.4(5.3)$ & $27.7(5.7)$ & $29.7(5.5)$ \\
\hline Median (range) maternal parity & $1.3(0-7)$ & $1.5(0-7)$ & $1.5(0-8)$ \\
\hline Immunisation uptake* & & & \\
\hline Any immunisation & $46(30)$ & $42(26)$ & $45(32)$ \\
\hline Primary course & $25 / 76(33)$ & $24 / 82(29)$ & $23 / 74(31)$ \\
\hline Measles, mumps, and rubella & $21 / 77(27)$ & $18 / 77(23)$ & $22 / 65(34)$ \\
\hline
\end{tabular}

${ }^{*} 95 \%$ Confidence intervals for difference in proportion between intervention groups and control group (values are percentages): any immunisation-intervention $A-2.3$ (-13.0 to 8.4), intervention $B-6.0$ (-16.4 to 4.4); primary course-intervention A 2.2 ( -12.9 to 17.3$)$, intervention $B-1.5$ ( -15.9 to 12.9$)$; measles, mumps, and rubella-intervention A -6.5 ( -21.7 to 8.7$)$, intervention $B-9.8$ ( -24.7 to 5.1$)$.

can improve uptake, ${ }^{5}$ although these approaches would benefit from more formal evaluation. More use should be made of randomised controlled trials to evaluate interventions to promote uptake of preventive services in primary care.

We thank the child health support team at the Welsh Health Common Services Authority for providing immunisation data; Mrs Margaret Morgan, Cardiff Community Healthcare NHS Trust, for her invaluable assistance; and Dr Frank Dunstan, Department of Medical Statistics and Computing, University of Wales College of Medicine, for statistical advice.

Contributors: MZM helped design the protocol, collected and analysed the data, and helped write the article. MRE conceived, designed, and supervised the study; wrote the article; and is the guarantor.

Funding: None.

Conflict of interest: None.

1 Brambleby P, Hanrahan J. Measles immunisation non-acceptance: validation of computer-held records and raising the vaccine uptake at early school age: the Maidstone experience. Public Health 1989;103:289-94. school age: the Maidstone experience. Public Health 1989;103:289-94.
Newport MJ, Conway SP. Experience of a specialist service for advice on childhood immunisation. J Infect 1993;26:295-300.

3 Crittenden P, Rao M. The immunisation coordinator: improving uptake of childhood immunisation. Commun Dis Rep CDR Rev 1994;4:R79-81.

4 Stehr-Green PA, Dini EF, Lindergren ML, Patriarca PA. Evaluation of telephone computer-generated reminders to improve immunisation coverage at inner city clinics. Public Health Reports 1993;108:426-30.

5 Peckham C, Bedford H, Seturia Y, Ades A. The Peckham report-national immunisation study: factors influencing immunisation uptake in childhood. London: Action for the Crippled Child, 1989

(Accepted 6 May 1998)

\section{Memorable patients Doing as they are told}

We all worry about patients' compliance. However, this is not the hazard. Occasionally advice can be taken too literally.

A young woman brought her baby to see me on account of nappy rash. The baby did not look ill and I asked the mother to undress her. I was horrified by the sight of a baby seemingly consisting of skin and bones. The only time I had seen anything like it was an illustration of marasmus in a textbook. On inquiring what kind of food the baby was having, the mother told me that it was Robinson's Patent Barley. "How was it made up?" "With water." "What else do you give her?" A blank stare. "No milk?" "No, my mother said I was brought up on Robinson's Patent Barley and I was always a bonny baby." The mother had obviously failed to mention that Robinson's Patent Barley was to be given in addition to and not instead of milk.
Once I was called to see a man in his 60 s because "his legs had turned blue." I found a slightly obese man, fussed over by his wife. He had the most extensive ecchymoses on both legs and also on other parts of his body. On inquiry it turned out that he had had a duodenal ulcer some years before. He was then advised to have plenty of milk drinks and milk puddings. That was indeed the diet his wife kept him on to the exclusion of all other food; she was very proud of it. Thus I saw what must have been the only case of scurvy in south Yorkshire.

Perhaps we are sometimes too emphatic and not sufficiently explicit in advising our patients.

Otto Fleming, retired general practitioner, Sheffield 